\title{
Assurance des Médecins Suisses société coopérative
}

RolfO. Heimgartner, directeur

Correspondance:

Assurance des Médecins Suisses société coopérative

Länggassstrasse 8

CH-3000 Berne 9

tél. 0313012555

fax 0313025156

versa@versa.ch

www.versa.ch

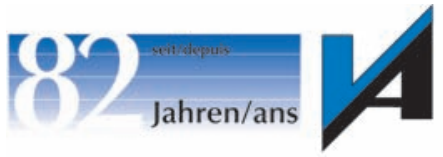

Le 17 mai 2008 s'est tenue la $82^{\mathrm{e}}$ assemblée ordinaire des délégués de l'Assurance des Médecins Suisses société coopérative sous la présidence du Docteur J. M. Fritzsche à l'hôtel Les Trois Rois à Bâle.

Dix-neuf délégués étaient présents, ainsi que Messieurs Dr méd. Otto P. Haab, Président d'honneur, Küssnacht; Peter W. Möschler, actuaire, Berne; Richard Schaller, actuaire, Weissensberg (D); Jakob Burkhard, directeur suppléant; ainsi qu'Armin Imoberdorf, Ernst \& Young AG, Berne; et Fritz Jakober, gestionnaire de fortune, Glaris.

L'économie roulant à plein régime durant l'année en revue ainsi que les prix des matières premières en constante progression ont conduit à une nette augmentation de l'inflation. Les banques émettrices se sont donc vues contraintes de freiner l'évolution conjoncturelle par une augmentation des taux, afin de combattre les risques de hausse des prix. Ainsi les intérêts à court et à long terme ont augmenté jusqu'en milieu d'année dans le monde entier. Les bourses d'actions ont profité jusqu'à ce moment des bénéfices d'entreprises réjouissants et ont atteint une progression d'environ 10\%. L'irruption de la crise hypothécaire et immobilière aux Etats-Unis a secoué les marchés financiers et les placeurs de fonds sont devenus moins enclins au risque. De nombreuses positions spéculatives ont été liquidées. Ceci a conduit à un déplacement vers le Franc suisse sûr et donc à une revalorisation du Franc suisse, précédemment faible, ainsi qu'à des ventes parfois massives sur les marchés des actions, de façon à ce que les gains atteints jusqu'en fin d'année soient perdus en grande partie. Les placements d'Etat, réputés sûrs, étaient par contre très recherchés.

L'éclosion de la bulle immobilière aux EtatsUnis devrait conduire à un refroidissement des activités économiques en Amérique et l'économie mondiale ne devrait pas non plus en rester épargnée. Ainsi les marchés financiers vont-ils vers une année qui sera empreinte d'espoir et de crainte.

La somme du bilan se monte, pour l'exercice 2007, à Fr. 1049841000.-.

Les placements en capitaux se répartissent de la manière suivante:
Titres à intérêt fixe

Fr. 535902000 .-

Actions et fonds de placement

Parts sur fondations de placement

Immeubles

Hypothèques

Prêts sur polices

Crédits d'investissement

Placements à long terme, call

Instruments financiers dérivés

Fr. 54069000 .

Fr. 79790000 .-

Fr. 201501 000.-

Fr. $108284000 .-$

Fr. 635000.

Fr. $254000 .-$

Fr. 20975000 .

Fr. 5484000 .-

L'assemblée des délégués approuve à l'unanimité le rapport de gestion, le bilan et le compte d'exploitation de l'exercice 2007 et accorde sa décharge au comité du Conseil d'administration, au Conseil d'administration et à la Direction, pour la gestion de l'exercice écoulé.

Se ralliant à la proposition du Conseil d'administration, l'assemblée des délégués décide, à l'unanimité, de répartir le bénéfice d'exploitation restant après bonification et répartition aux réserves, soit Fr. 553701.-, de la manière suivante:

\begin{tabular}{ll} 
Attribution aux réserves générales & Fr. 550 000.- \\
Attribution au fonds de secours & Fr. $3701 .-$ \\
\hline Fr. 553701.- &
\end{tabular}

Pour la prochaine durée de mandat en qualité de Conseil d'administration, soit de l'assemblée des délégués 2008 à l'assemblée des délégués 2011, les personnes suivantes sont proposées et élues à l'unanimité :

- Dr méd. Jürg M. Fritzsche, président

- Dr méd. Balthasar Leuzinger

- Dr méd. Rolf Lehmann

- Prof. Dr méd. dent. Max O. Schmid

- Dr méd. vét. Pierre Berthold

- Dr sc. math. Hanspeter Tobler

- Prof. Dr rer. pol. Heinz Zimmermann

Pour la période allant de l'assemblée des délégués de l'année 2008 jusqu'à l'assemblée des délégués de l'année 2009 l'organe de révision actuel, Ernst \& Young AG, Berne, a été réélu à l'unanimité. 